\title{
Orange Phosphorescent Organic Light-emitting Diodes Using a Spirobenzofluorene-type Phospine Oxides as Host Materials
}

\author{
Young-Min Jeon,,${ }^{\ddagger}$ In-Ho Lee, ${ }^{\dagger}$ Chil-Won Lee,,$\#$ Jun-Yeob Lee, ${ }^{\S}$ and Myoung-Seon Gong ${ }^{\dagger, \downarrow, *}$ \\ ${ }^{\dagger}$ Department of Nanobiomedical Science and WCU Research Center of Nanobiomedical Science, Dankook University, \\ Chungnam 330-714, Korea. E-mail: msgong@dankook.ac.kr \\ ${ }^{\star}$ Department of Chemistry and Institute of Basic Science, Dankook University, Chungnam 330-714, Korea \\ ${ }^{\S}$ Department of Polymer Engineering, Dankook University, Yongin, Kyung-gi 448-701, Korea \\ ${ }^{\#}$ OLED Team, Daejoo Electronic Materials, Siheung, Kyung-gi 429-848, Korea \\ Received July 29, 2010, Accepted September 2, 2010
}

\begin{abstract}
Spiro-type orange phosphorescent host materials, 9-diphenylphosphine oxide-spiro[fluorene-7,9'-benzofluorene] (OPH-1P) and 5-diphenylphosphine oxide-spiro[fluorene-7,9'-benzofluorene] (OPH-2P) were successfully prepared by a lithiation reaction followed by a phosphination reaction with diphenylphosphinic chloride. The EL characteristics of OPH-1P and OPH-2P as orange host materials doped with iridium(III) bis(2-phenylquinoline)acetylacetonate $\left(\operatorname{Ir}(\mathrm{pq})_{2} \mathrm{acac}\right)$ were evaluated. The electroluminescence spectra of the ITO $(150 \mathrm{~nm}) / \mathrm{DNTPD}(60 \mathrm{~nm}) / \mathrm{NPB}(30 \mathrm{~nm}) /$ OPH-1P or OPH-2P: $\operatorname{Ir}(\mathrm{pq})_{2} \mathrm{acac}(30 \mathrm{~nm}) / \mathrm{BCP}(5 \mathrm{~nm}) / \mathrm{Alq}_{3}(20 \mathrm{~nm}) / \mathrm{LiF}(1 \mathrm{~nm}) / \mathrm{Al}(200 \mathrm{~nm})$ devices show a narrow emission band with a full width at half maximum of $75 \mathrm{~nm}$ and $\lambda_{\max }=596 \mathrm{~nm}$. The device obtained from OPH-1P doped with $3 \% \operatorname{Ir}(\mathrm{pq})_{2}$ acac showed an orange color purity of $(0.580,0.385)$ and an efficiency of $(14 \mathrm{~cd} / \mathrm{A}$ at $7.0 \mathrm{~V})$. The ability of the OPH-P series to combine a high triple energy with a low operating voltage is attributed to the inductive effect of the $\mathrm{P}=\mathrm{O}$ moieties and subsequent energy lowering of the LUMO, resulting in the enhancement of both the electron injection and transport in the device. The overall result is a device with an $\mathrm{EQE}>8 \%$ at high brightness, but operating voltage of less than $6.4 \mathrm{~V}$, as compared to the literature voltages of $\sim 10 \mathrm{~V}$.
\end{abstract}

Key Words: Phosphine oxide, Orange, Host, Phosphorescent OLED, Spirobenzofluorene

\section{Introduction}

Organic light-emitting diodes (OLEDs) have attracted much attention in recent years owing to their potential as low-cost and large-area full color displays and solid-state lightings. Phosphorescent organic light-emitting devices (PHOLED) have become more and more important in recent years because of their high efficiencies with triplet emission. In particular, electro-phosphorescent OLEDs (or PHOLED) have outstanding performance because they take advantage of both singlet $(\leq 25 \%)$ and triplet excitons $(\leq 75 \%)$, achieving excellent external quantum efficiency and power efficiency. ${ }^{1-4}$ Due to their triplet emission, the an internal efficiency can be increased to as high as $100 \%$ can theoretically be achieved is particularly important for practical applications, in which the device is expected to operate at a low voltage and to consume less power.

Recently, phosphorous-containing organic compounds, especially organic diphosphine oxides, have been used to obtain low voltage PHOLED devices. ${ }^{5-7}$ Phosphine oxide-based electron transport materials have also been reported and triphenylphosphine oxide has been used as an electron transport material and found to decrease the driving voltage of OLEDs. ${ }^{8,9}$

Spiro-type derivatives containing fluorene and benzofluorene have received a great deal of attention as fluorescent materials for OLEDs, because asymmetrical spiro compounds having naphthalene groups can not only preserve their inherent characteristics, such as their morphological stability, high glass transition temperature and amorphous properties, but also provide a variety of substituents on the aromatic ring of the spiro molecules, resulting in the formation of conjugation controlled
OLED host and dopant materials. ${ }^{10-13}$ A lot of papers deal with the use of spiro[fluorene-7,9'-benzofluorene] as an organic electroluminescent host and dopant material. ${ }^{10-18}$ Spiro-type phosphine oxide derivatives have been prepared and derivatives based on substitution at the 2-position of the spiro[fluorene-7,9'benzofluorene] have been investigated. ${ }^{18}$

In this work, the spirobenzofluorene based phosphine oxide compounds, 9-diphenylphosphine oxide-spiro[fluorene-7,9'benzofluorene] (OPH-1P) and 5-diphenylphosphine oxide-spiro [fluorene-7,9'-benzofluorene] (OPH-2P), were prepared by introducing diphenyl phosphine oxide at the 5- and 9-positions on the spiro[fluorene-7,9'-benzofluorene] and their use as orange phosphorescent host materials was evaluated. The device performances of the orange PHOLEDs with the OPH-1P and OPH$2 \mathrm{P}$ hosts were investigated according to the doping concentration of red dopant.

\section{Experimental}

Chemicals and instruments. Diphenylphosphinic chloride (TCI Chem. Co.) and butyllithium (2.5 M solution in hexane, Aldrich Chem. Co.) were used without further purification. Tetrahydrofuran was distilled over sodium and calcium hydride. 9-Bromospiro[fluorene-7,9'-benzofluorene] and 5-bromospiro [fluorene-7,9'-benzofluorene] were prepared as previously reported. ${ }^{10}$

${ }^{1} \mathrm{H}-\mathrm{NMR}$ and ${ }^{13} \mathrm{C}$-NMR spectra were recorded on a Bruker Avance 500 (500 MHz for ${ }^{1} \mathrm{H}$ and $125 \mathrm{MHz}$ for ${ }^{13} \mathrm{C}$ ) spectrometer. The UV-visible spectra were obtained by means of a UV-visible spectrophotometer (Shimadzu UV-1601PC). The 
photoluminescence spectra were recorded on a fluorescence spectrophotometer (Jasco FP-6500). The DSC measurements were performed on a Shimadzu DSC-60 differential scanning calorimeter under nitrogen at a heating rate of $10{ }^{\circ} \mathrm{C} / \mathrm{min}$. The TGA measurements were performed on a Shimadzu TGA-50 thermogravimetric analyzer at a heating rate of $5^{\circ} \mathrm{C} / \mathrm{min}$. The low and high resolution mass spectra were recorded using a JEOL JMS-AX505WA spectrometer in FAB mode.

9-Diphenylphosphine oxide-spiro[fluorene-7,9'-benzofluorene](OPH-1P). 9-Bromospiro[fluorene-7,9'-benzofluorene] $(3 \mathrm{~g}, 6.73 \mathrm{mmol}$ ) was dissolved in $50 \mathrm{~mL}$ of anhydrous tetrahydrofuran under argon and cooled to $-78^{\circ} \mathrm{C}$. $n$-Butyllithium (1.5 eq, $2.5 \mathrm{M}$ in hexane, $5.4 \mathrm{~mL}$ ) was added dropwise to give a bright yellow solution that thickened to a slurry. The stirring was continued for $1 \mathrm{~h}$ at $-78{ }^{\circ} \mathrm{C}$, after which $2.4 \mathrm{~mL}(10.1 \mathrm{mmol})$ of diphenylphosphinic chloride was added, giving a clear, pale yellow solution. After the solution was stirred for $12 \mathrm{~h}$ at $-78^{\circ} \mathrm{C}$, the organic phase was separated and washed with water and brine solution. The organic layer was removed under reduced pressure. Purification with column chromatography using silica gel eluting with a mixture of dichloromethane $/ n$-hexane $(\mathrm{v} / \mathrm{v}=$ $2 / 1$ ) followed by recrystallization in toluene to give OPH-1P as a white solid.

Yield $72 \%$. mp $264{ }^{\circ} \mathrm{C} .{ }^{1} \mathrm{H}$ NMR $\left(500 \mathrm{MHz}, \mathrm{CDCl}_{3}\right) \delta 8.78-$ 8.76 (d, 1H, Ar-CH-benzene), 8.47-8.46 (d, 1H, Ar-CH-benzene), 7.89-7.88 (d, 1H, Ar-CH-naphthalene), 7.84-7.82 (d, 2H, Ar-CH-benzene), 7.72-7.70 (t, 1H, Ar-CH-benzene), 7.65-7.64 (d, 1H, Ar-CH- benzene), 7.57-7.56 (d, 2H, Ar-CH-benzene), 7.56-7.55 (t, 1H, Ar-CH-fluorene), 7.56-7.55 (m, 3H, Ar-CHbenzene), 7.51-7.49 (m, 2H, Ar-CH-fluorene), 7.39-7.38 (m, 7H, Ar-CH-benzene), 7.07-7.05 (t, 2H, Ar-CH- benzene), 6.816.79 (d, 1H, Ar-CH-benzene), 6.67-6.65 (d, 2H, Ar-CH-benzene), ${ }^{13} \mathrm{C} \mathrm{NMR}\left(\mathrm{CDCl}_{3}\right) \delta 149.4,146.9,146.8,142.5,132.3$, 132.2, 132.0, 131.9, 130.4, 129.7, 128.6, 128.5, 128.3, 128.0, $127.4,125.9,124.0,123.7,122.1,120.5,77.4,77.2,76.9,66.4$. FT-IR $\left(\mathrm{KBr}, \mathrm{cm}^{-1}\right)$ 3054, 3041 (aromatic C-H), $1314(\mathrm{P}=\mathrm{O})$. Anal. Calcd for $\mathrm{C}_{4} \mathrm{H}_{25} \mathrm{H}$ (Mw, 566.63): C, 86.91; H, 4.80; P, 5.47. Found: C, 86.94; H, 4.76; P, 5.41. MS (FAB) $m / z 566.18$ $\left[(\mathrm{M}+1)^{+}\right]$. UV-vis $(\mathrm{THF}): \lambda_{\max }($ Absorption $)=345 \mathrm{~nm}, \lambda_{\max }$ $($ Emission $)=395 \mathrm{~nm}$.

5-Diphenylphosphine oxide-spiro[fluorene-7,9'-benzofluorene](OPH-2P). 5-Bromospiro[fluorene-7,9'-benzofluorene] $(2.5 \mathrm{~g}, 5.61 \mathrm{mmol})$ was dissolved in $40 \mathrm{~mL}$ of anhydrous tetrahydrofuran under argon and cooled to $-78^{\circ} \mathrm{C}$ and 1.5 equivalents of $n$-butyllithium ( $2.5 \mathrm{M}$ in hexanes, $4.5 \mathrm{~mL}$ ) was added dropwise to give a bright yellow solution that thickened to a slurry. The stirring was continued for $1 \mathrm{~h}$ at $-78^{\circ} \mathrm{C}$ after which $2.0 \mathrm{~mL}$ $(8.4 \mathrm{mmol})$ of diphenylphosphinic chloride was added giving a clear, pale yellow solution. The solution was stirred for $12 \mathrm{~h}$ at $-78^{\circ} \mathrm{C}$. The organic phase was separated, washed with water and brine solution and the organic layer was removed under reduced pressure. Purification with column chromatography using silica gel eluting with a mixture of dichloromethane/ $n$-hexane $(\mathrm{v} / \mathrm{v}=2 / 1)$ followed by recrystallization in toluene to give $\mathrm{OPH}-2 \mathrm{H}$ as a white solid.

Yield 74\%. mp $268{ }^{\circ} \mathrm{C} .{ }^{1} \mathrm{H}$ NMR $\left(500 \mathrm{MHz}, \mathrm{CDCl}_{3}\right) \delta 8.92-$ 8.90 (d, 1H, Ar-CH-benzene), 8.58-8.56 (d, 1H, Ar-CH-benzene), 8.49-8.48 (d, 1H, Ar-CH-naphthalene), 7.70-7.69 (d,
2H, Ar-CH-benzene), 7.69-7.67 (t, 1H, Ar-CH-benzene), 7.487.44 (m, 8H, Ar-CH-benzene), 7.34-7.31 (d, 2H, Ar-CH-benzene), 7.25-7.21 (m, 5H, Ar-CH-benzene), 7.10-7.07 (t, 2H, Ar-CH-benzene), 7.05-7.04 (d, 1H, Ar-CH-benzene), 6.66-6.64 (d, 2H, Ar-CH-benzene), 6.52-6.51 (d, 1H, Ar-CH-benzene), ${ }^{13} \mathrm{C} \mathrm{NMR}\left(\mathrm{CDCl}_{3}\right) \delta 150.0,147.0,142.3,142.2,132.0,131.9$, $131.7,129.1,128.5,128.4,128.3,128.0,127.9,127.3,126.8$, 124.6, 124.5, 124.0, 123.9, 120.1, 77.4, 77.2, 76.9. FT-IR (KBr, $\left.\mathrm{cm}^{-1}\right)$ 3061, 3056 (aromatic C-H), $1310(\mathrm{P}=\mathrm{O})$. Anal. Calcd for $\mathrm{C}_{4} \mathrm{H}_{25} \mathrm{H}$ (Mw, 566.63): C, 86.91; H, 4.80; P, 5.47. Found: C, 86.91; H, 4.78; P, 5.43. MS (FAB) $m / z 566.18\left[(\mathrm{M}+1)^{+}\right]$. UV-vis $(\mathrm{THF}): \lambda_{\max }($ Absorption $)=356 \mathrm{~nm}, \lambda_{\max }($ Emission $)=385 \mathrm{~nm}$.

PHOLED fabrication. PHOLEDs were fabricated with a configuration of (ITO, $150 \mathrm{~nm}$ ) $/ N, N^{\prime}$-diphenyl- $N, N^{\prime}$-bis-[4(phenyl- $m$-tolyl-amino)-phenyl]-biphenyl-4,4'-diamine (DNT$\mathrm{PD}, 60 \mathrm{~nm}) / N, N^{\prime}$-di(1-naphthyl)- $N, N^{\prime}$-diphenylbenzidine (NPB, $30 \mathrm{~nm}$ )/9-diphenylphosphine oxide-spiro[fluorene-7,9'-benzofluorene] (OPH-1P) or 5-diphenylphosphine oxide-spiro[fluorene-7,9'-benzofluorene] (OPH-2P): iridium(III) bis(2-phenylquinoline)acetylacetonate $\left(\operatorname{Ir}(\mathrm{pq})_{2}\right.$ acac $)(30 \mathrm{~nm}, \mathrm{x} \%) / 2,9-$ dimethyl-4,7-diphenyl-1,10-phenanthroline (BCP, $5 \mathrm{~nm}) / \operatorname{tris}(8-$
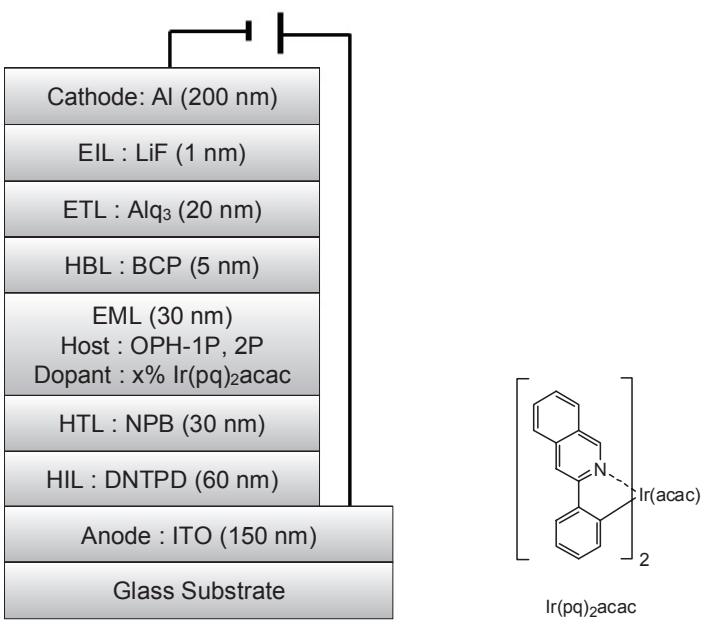

$\operatorname{lr}(\mathrm{pq})_{2} \mathrm{acac}$

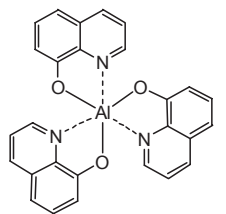

$\mathrm{Alq}_{2}$

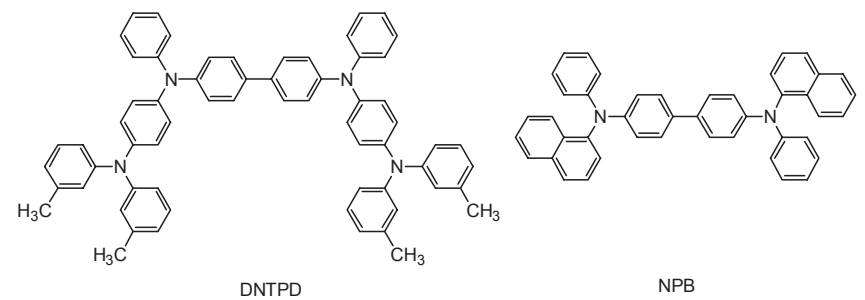

Figure 1. The device configuration and the chemical structure of the materials used in the devices. 
hydroxyquinoline)aluminum (Alq3, $20 \mathrm{~nm}) / \mathrm{LiF}(1 \mathrm{~nm}) / \mathrm{Al}(200$ $\mathrm{nm})$, in which OPH-1P or OPH-2P acted as the phosphorescent host emitters, $\operatorname{Ir}(\mathrm{pq})_{2}$ acac as the dopant material, $\mathrm{Alq}_{3}$ as the electron-transporting layer, and $\mathrm{BCP}$ as the hole/exciton blocking layer. All organic materials except for the dopants were deposited at a deposition rate of $1 \AA / \mathrm{s}$. Various doping concentrations of $\operatorname{Ir}(\mathrm{pq})_{2}$ acac were used, viz. 1, 3 and 10\%. The devices were encapsulated with a glass lid and a $\mathrm{CaO}$ getter after cathode deposition. The current density-voltage-luminance and electroluminescence characteristics of the blue fluorescent OLEDs were measured with a Keithley 2400 source measurement unit and CS 1000 spectroradiometer, respectively.

\section{Results and Discussion}

Synthesis and characterization. The synthetic route to $\mathrm{OPH}-$ $1 \mathrm{P}$ and OPH-2P is shown in Scheme 1. The OPH-P series were synthesized by lithiation followed by a phosphination reaction with diphenylphosphinic chloride. ${ }^{19}$ The synthetic yields of OPH-1P and OPH-2P were $74 \%$ and $76 \%$, respectively. The purity of OPH-1P and OPH-2P was over $99 \%$ after purification by column chromatography. All of the OPH-P series are completely soluble in common organic solvents, which makes them eligible for solution phase characterization. The chemical structures and compositions of the resulting precursor and spirocompounds were characterized by ${ }^{1} \mathrm{H}-\mathrm{NMR},{ }^{13} \mathrm{C}-\mathrm{NMR}$, FT-IR, elemental analysis and GC-MS.

Optical properties and energy levels. The UV-vis absorption and room temperature photoluminescence (PL) spectra of the spiro/phosphine oxide hybrids were recorded in tetrahydrofuran solution $\left(\mathrm{ca}, 10^{-5} \mathrm{~mol} / \mathrm{L}\right)$ and in the solid state as shown in Figure 2 and Table 1. The solid-state absorption spectra of the OPH-P series were similar to that of their solutions. The solution absorption maxima were observed at $345 \mathrm{~nm}$ for OPH$1 \mathrm{P}$ and $356 \mathrm{~nm}$ for OPH-2P. The absorption maxima of OPH-1P and OPH-2P films appeared at 350 and $362 \mathrm{~nm}$ and were redshifted by 5 and $6 \mathrm{~nm}$, respectively. The emission maxima of OPH-1P and OPH-2P were located at 395 and $385 \mathrm{~nm}$ in solution, respectively, while the solid state absorption maxima were observed at $404 \mathrm{~nm}$ for OPH-1P and $401 \mathrm{~nm}$ for OPH-2P. Although the solid film of the OPH-P series exhibited a similar emission in the UV region, a new broad emission peak was

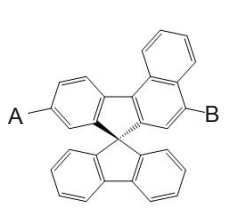

1) $\mathrm{A}=\mathrm{Br}, \mathrm{B}=\mathrm{H}$

2) $A=H, B=B r$
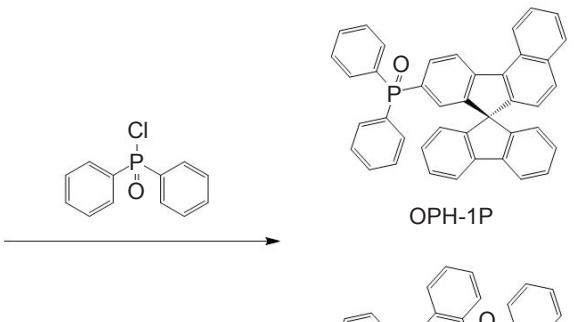

OPH-1P

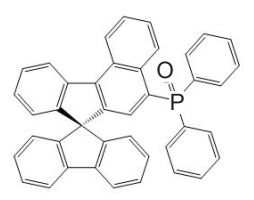

OPH-2P
Scheme 1. Chemical structures of Orange phosphorescent host materials
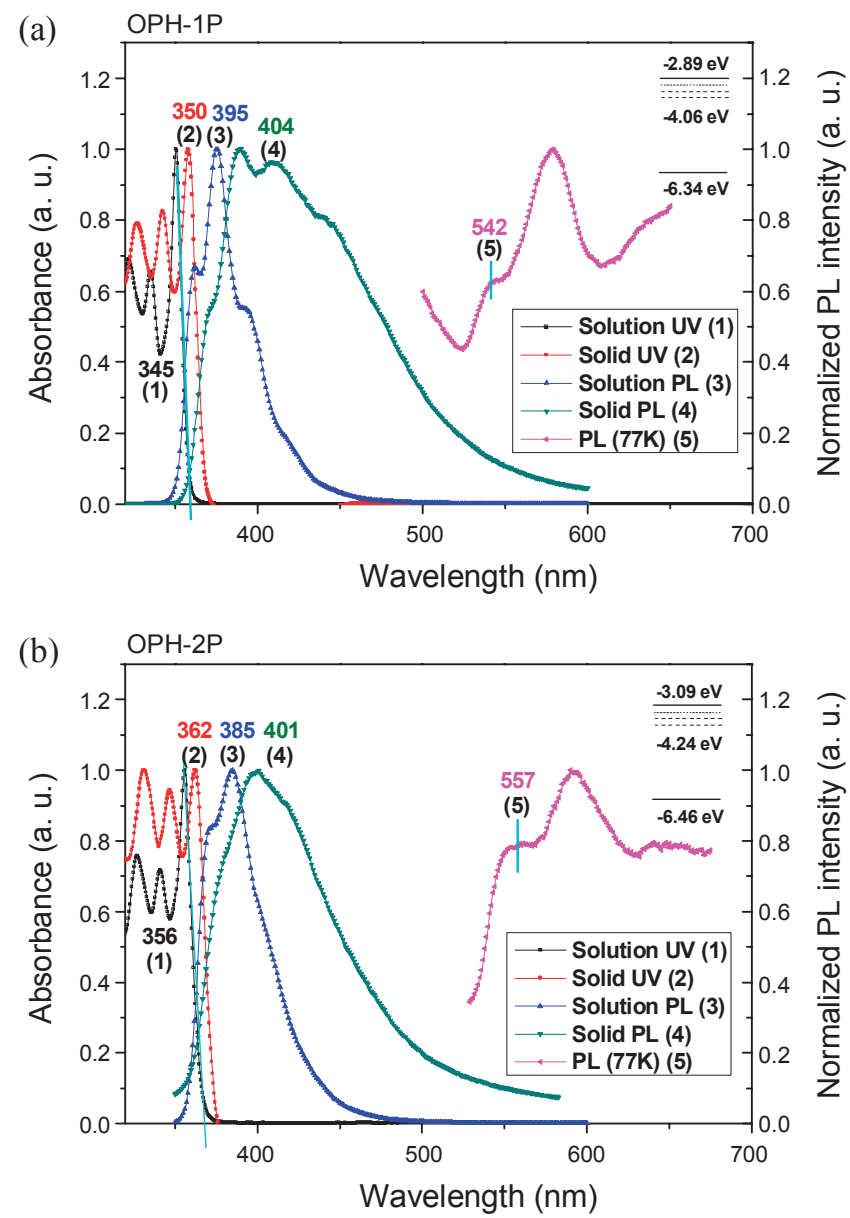

Figure 2. Normalized absorption, photoluminescence spectra and energy diagram of (a) OPH-1P and (b) OPH-2P.

Table 1. Thermal properties and EL properties of the devices obtained from two host and $\operatorname{Ir}(\mathrm{pq})_{2}$ acac dopant materials

\begin{tabular}{|c|c|c|c|}
\hline \multirow[b]{2}{*}{ Properties } & Devices & OPH-1P & OPH-2P \\
\hline & & \multicolumn{2}{|c|}{$\operatorname{Ir}(\mathrm{pq})_{2} \mathrm{acac}$} \\
\hline \multirow{13}{*}{$\begin{array}{c}\text { EL } \\
\text { at } 7 \mathrm{~V}\end{array}$} & $\lambda_{\max }(\mathrm{nm})$ & 596 & 595 \\
\hline & FWHM(nm) & 75 & 74 \\
\hline & $\mathrm{mA} / \mathrm{cm}^{2}$ & 10.3 & 25.1 \\
\hline & $\mathrm{cd} / \mathrm{A}^{a}$ & 14 & 6.98 \\
\hline & $\mathrm{cd} / \mathrm{A}^{b}$ & $14(7 \mathrm{~V})$ & $8.88(5 \mathrm{~V})$ \\
\hline & $\operatorname{lm} / \mathrm{W}^{a}$ & 6.97 & 3.46 \\
\hline & $\operatorname{lm} / \mathrm{W}^{b}$ & $7.23(6.5 \mathrm{~V})$ & $6.17(5 \mathrm{~V})$ \\
\hline & $\mathrm{cd} / \mathrm{m}^{2}$ & 1446 & 1751 \\
\hline & CIE-x & 0.580 & 0.586 \\
\hline & CIE-y & 0.385 & 0.394 \\
\hline & $\mathrm{EQE}^{a}(\%)$ & 8.26 & 4 \\
\hline & $\mathrm{EQE}^{b}(\%)$ & $8.26(7 \mathrm{~V})$ & $5.12(5 \mathrm{~V})$ \\
\hline & $\mathrm{V}_{\mathrm{opt}}^{c}$ & $6.34 \mathrm{~V}$ & $6.11 \mathrm{~V}$ \\
\hline \multirow{3}{*}{$\begin{array}{l}\text { Thermal } \\
\text { properties }\end{array}$} & $T_{g}^{d}$ & $126^{\circ} \mathrm{C}$ & $123^{\circ} \mathrm{C}$ \\
\hline & $T_{m}^{e}$ & $264^{\circ} \mathrm{C}$ & $268^{\circ} \mathrm{C}$ \\
\hline & $T_{d}^{f}$ & $488^{\circ} \mathrm{C}$ & $444^{\circ} \mathrm{C}$ \\
\hline
\end{tabular}

${ }^{a}$ Values at $7 \mathrm{~V} ;{ }^{b}$ values at a maximum peak; $V_{\text {opt }}$, operating voltage at a specified current; ${ }^{c}$ Reported at $800 \mathrm{~cd} / \mathrm{m}^{2} ;{ }^{d}$ glass transition temperature, ${ }^{e}$ melting temperature, ${ }^{f}$ decomposition temperature. 
(a)

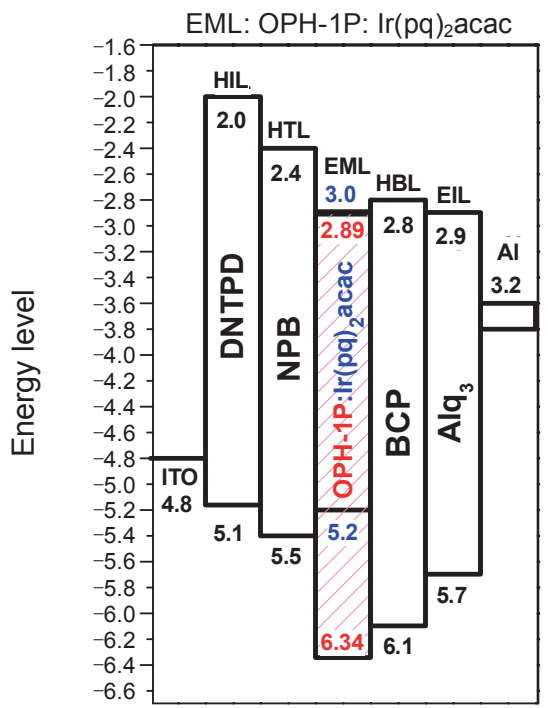

(b)

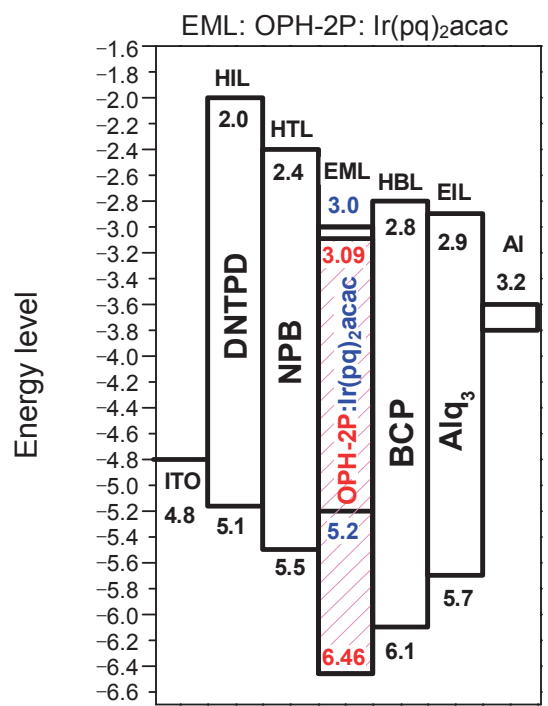

Figure 3. Energy level diagrams of the (a) OPH-1P: $\operatorname{Ir}(\mathrm{pq})_{2}$ acac and (b) OPH-2P: $\operatorname{Ir}(\mathrm{pq})_{2}$ acac devices.

also observed. The excitation spectra indicated that both the UV emission and broad lower energy emission originated from the same ground state, suggesting that the latter was an excimer emission.

Figure 3 presents a schematic energy-level alignment of the device. The energy levels of the new host materials were measured by cyclic voltammetry and estimated from their absorption and PL spectra. The triplet energies of the spirobenzofluorenephosphine oxide derivatives were measured from the phosphorescence spectra in tetrahydrofuran glasses at $77 \mathrm{~K}$. We estimated the triplet energy band gaps of OPH-1P and OPH-2P to be 2.28 and $2.22 \mathrm{eV}$, respectively. It can be seen that the highest occupied molecular orbital (HOMO) and lowest unoccupied molecular orbital (LUMO) of OPH-1P are located at 6.34 and $2.89 \mathrm{eV}$ and those of OPH-2P are located at 6.46 and $3.09 \mathrm{eV}$, respectively. The OPH-P host materials have lower LUMO and HOMO values than those of common phosphorescent host materials as summarized in Table 1. Because the effect of the

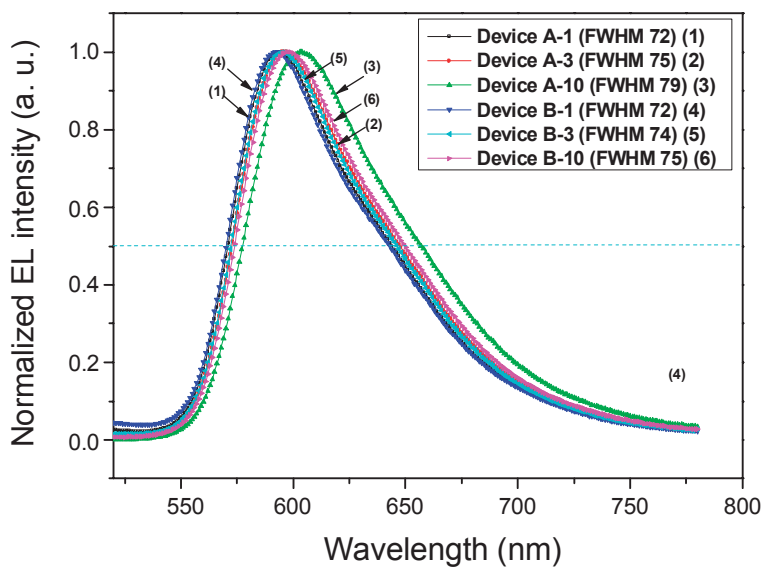

Figure 4. Electroluminescence spectra of orange PHOLEDs with $\mathrm{OPH}-1 \mathrm{P}$ and $\mathrm{OPH}-2 \mathrm{P}$ as a host according to doping concentration.

phosphine oxide substituent on the mother spirobenzofluorene is weak, it is not easy for holes to transfer from the hole transfer layer to the host layer. Therefore, the OPH-P host materials are not expected to be good ones, because of these electrical characteristics.

Themal properties. The thermal properties of the spiro-phosphine oxide derivatives were evaluated by thermogravimetric analysis (TGA) and differential scanning calorimetry (DSC). The purified samples of OPH-1P and OPH-2P showed melting points $\left(T_{m}\right)$ of 264 and $268{ }^{\circ} \mathrm{C}$ after sublimation, respectively, as shown in Table 1. On the second heating scan, no melting points were observed, even though the specimens were given enough time to cool in air. Once they become an amorphous solid, they do not revert to the crystalline state at all. After the samples had cooled to room temperature, a second DSC scan was performed at $10{ }^{\circ} \mathrm{C} / \mathrm{min}$ and revealed a high glass transition temperature $\left(T_{\mathrm{g}}\right)$ of $126{ }^{\circ} \mathrm{C}$, because of their rigid spiro-type backbone. The thermal decomposition temperatures for OPH-1P and $\mathrm{OPH}-2 \mathrm{P}$, identified as the peaks of the derivatives of the weight losses, are 488 and $444{ }^{\circ} \mathrm{C}$ respectively. As a result, the amorphous glassy state of the transparent film of the two host materials makes them good candidates for use as EL materials.

EL properties. Figure 4 shows the EL emission spectra of the six devices. In order to find the optimized dopant concentration, the EL spectra were gathered from OPH-1P and OPH-2P doped with $\operatorname{Ir}(\mathrm{pq})_{2}$ acac at various concentrations. The emission band increases with increasing dopant concentration from 1 to $10 \%$ by weight. The spectra of the six devices are quite similar to the PL solution spectra. This suggests that the same excited state species is responsible for both the PL and EL emissions, resulting from the triplet emission due to the $\operatorname{Ir}(\mathrm{pq})_{2}$ acac complex. The EL emission is dominated by the $\operatorname{Ir}(\mathrm{pq})_{2}$ acac complex emission peak at around $593-603 \mathrm{~nm}$, on the other hand no host emission was observed. This seems to indicate that the energy transfer from the OPH-1P or OPH-2P hosts to the $\operatorname{Ir}(\mathrm{pq})_{2}$ acac complex is quite efficient at the optimum dopant concentration used in this experiment. The full width at half maximum (FWHM $75 \mathrm{~nm}$ ) is relatively smaller, causing the color purity to be improved, which is quite consistent with the PL spectra.

The dependence of the chromaticity of the devices on the 


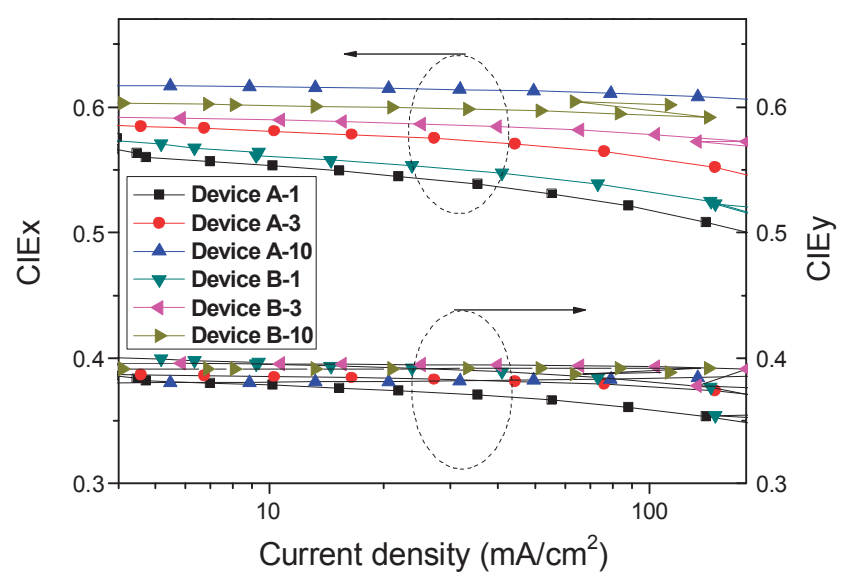

Figure 5. Stability of the chromaticity depicted by CIE coordination.

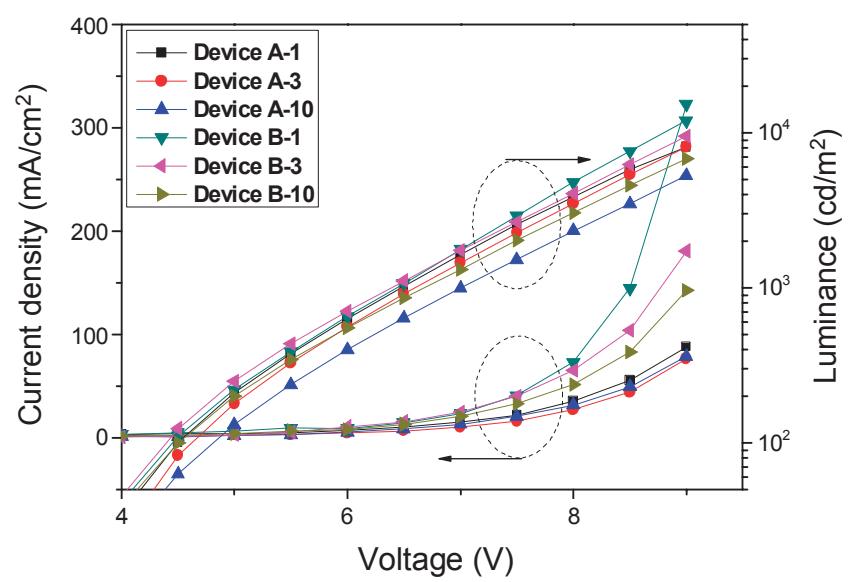

Figure 6. Dependence of current density and luminance on the applied voltage.

current density was measured for the purpose of evaluating their stability as shown in Figure 5. When the EL spectrum was converted into chromaticity coordinates on the CIE 1931 diagram, the stability of the chromaticity increased with increasing the current density and applied voltage. In addition, the stability of the color coordinates also increased with increasing dopant concentration. Especially the stability of the CIEy coordinates was better than that of the CIEx.

OLED device properties. The multilayer diodes have a structure of ITO $(150 \mathrm{~nm}) / \mathrm{DNTPD}(60 \mathrm{~nm}) / \mathrm{NPB}(30 \mathrm{~nm}) / \mathrm{OPH}-1 \mathrm{P}$ or OPH-2P:Ir(pq) $)_{2}$ acac $(30 \mathrm{~nm}, \mathrm{x} \%) / \mathrm{BCP}(5 \mathrm{~nm}) / \mathrm{Alq}_{3}(20 \mathrm{~nm}) /$ $\mathrm{LiF}(1 \mathrm{~nm}) / \mathrm{Al}(200 \mathrm{~nm})$. Six different multilayered devices were prepared by changing the dopant concentration. A-1, A-3, and A-10 were fabricated with OPH-1P doped using 1\%, 3\% and $10 \%$ of $\operatorname{Ir}(\mathrm{pq})_{2}$ acac, respectively, while devices B-1, B-3 and $\mathrm{B}-10$ made of the OPH-2P host were doped with 1\%, 3\% and $10 \%$ of $\operatorname{Ir}(\mathrm{pq})_{2}$ acac. When the doping concentration was increased to $10 \mathrm{wt} \%$, the luminance efficiency decreased due to the concentration quenching effect. Maximum luminescence efficiency was obtained in the red OHOLED with a doping concentration of $3 \%$. As a result, the device with OPH-1C: $3 \%$ $\operatorname{Ir}(\mathrm{pq})_{2} \mathrm{acac}$ showed a luminance efficiency of $14.0 \mathrm{~cd} / \mathrm{A}$ at $7 \mathrm{~V}$

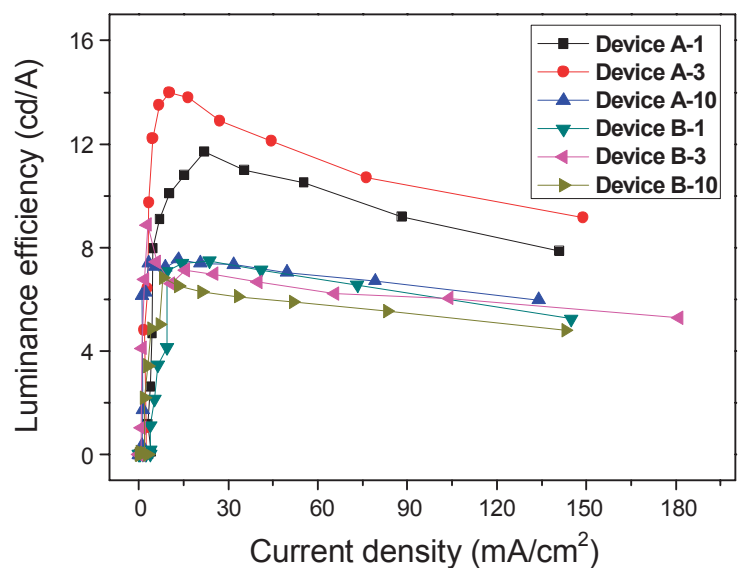

Figure 7. Luminance efficiency-current density characteristics of the device using $\mathrm{OPH}-1 \mathrm{P}$ and $\mathrm{OPH}-2 \mathrm{P}$ Host.

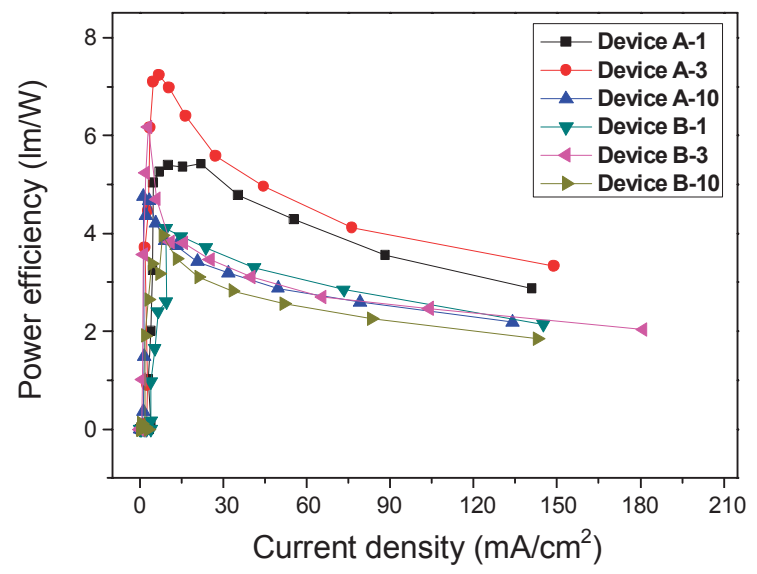

Figure 8. Power efficiency-current density characteristics of the device using OPH-1P and OPH-2P Host.

and quantum efficiency of $8.26 \%$, which is lower than that of the OPH-C series. ${ }^{20}$

Figure 6 shows the current density and luminance-voltage curves for the devices. The turn-on voltage is $3.5 \mathrm{~V}$. The maximum brightness was around $12,000 \mathrm{~cd} / \mathrm{m}^{2}$ (at $323 \mathrm{~mA} / \mathrm{cm}^{2}$ ) for device B-1, 9,559 cd/m (at $181 \mathrm{~mA} / \mathrm{cm}^{2}$ ) for device B-3, and $6,852 \mathrm{~cd} / \mathrm{m}^{2}$ (at $143 \mathrm{~mA} / \mathrm{cm}^{2}$ ) for device B-10. Device A-3 showed the highest brightness of $22,410 \mathrm{~cd} / \mathrm{m}^{2}$, which is two times of device B-3. Both the current density and luminance of the devices using OPH-2P are higher than those of OPH-1P in the same device structure. The phosphorescent device had a lower driving voltage of $4 \mathrm{~V}$ required to initiate light emission compared with that of the fluorescnet OLED.

Figure 7 shows the dependence of the luminance efficiency on the current density for the six electrophosphorescent devices with different doping concentrations. The maximum luminance efficiencies of devices A-1, A-3, and A-10 were determined to be $11.7 \mathrm{~cd} / \mathrm{A}$ (at $21.9 \mathrm{~mA} / \mathrm{cm}^{2}$ ), $14.0 \mathrm{~cd} / \mathrm{A}$ (at $10.3 \mathrm{~mA} / \mathrm{cm}^{2}$ ) and $7.55 \mathrm{~cd} / \mathrm{A}$ (at $13.2 \mathrm{~mA} / \mathrm{cm}^{2}$ ), respectively. Devices B-1, B-3, and B-10 exhibited lower luminance efficiencies than those of the devices obtained from OPH-1P. Device B-3 showed the highest luminance efficiency around $8.88 \mathrm{~cd} / \mathrm{A}$ (at $2.82 \mathrm{~mA} /$ 
$\mathrm{cm}^{2}$ ) in the device B group. When the doping concentration increased to $10 \mathrm{wt} \%$, an abrupt increase at the initial state and then gradual decreases of luminence efficiency were observed. These characteristics of poor efficiency of devices using OPH-2P are not unexpected due to the mismatch of the charge transport properties and energy level of the host materials.

Figure 8 shows the dependence of the power efficiency on the current density for the six electrophosphorescent devices with different doping concentrations. The A-3 device exhibited the highest performance at $6.0 \mathrm{~V}$ with a maximum power efficiency of $7.09 \mathrm{~lm} / \mathrm{W}$ at $4.95 \mathrm{~mA} / \mathrm{cm}^{2}$, which is ascribed to the larger number of excitons generated in the emitting layer. It is well known that dipole-dipole interactions of dopant molecules, which were randomly distributed or oriented, are one of the main factors of energy disorder in organic materials. ${ }^{21}$ At a low dopant concentration in the EML layer, the average distance between the dopant molecules is mainly determined by the dipole-dipole interactions. Therefore, the dopant molecules in OPH-1P or OPH-2P with $10 \%$ dopant concentration create additional energy disorder, which leads to potential fluctuations caused by the dipole-dipole interactions of the randomly distributed dopant molecules.

\section{Conclusion}

A series of new orange light emitting phosphine oxide-type host materials (OPH-1P, OPH-2P) were successfully prepared by the phosphination reaction of 5 or 9-bromo-spiro[fluorene7,9'-benzofluorene] with diphenylphosphinic chloride. The ability of the OPH-P series to combine a high energy transfer with a low operating voltage is attributed to the inductive effect of the $\mathrm{P}=\mathrm{O}$ moieties and subsequent energy lowering of the LUMO, resulting in the enhancement of both the electron injection and transport in the device. The overall result is a device with an EQE $>8 \%$ at a high brightness, but $V_{\text {opt }}<6.4 \mathrm{~V}$, as compared to the literature voltages of $\sim 10 \mathrm{~V}$.

\section{Reference}

1. Baldo, M. A.; O'Brien, D. F.; You, Y.; Shoustikov, A.; Sibley, S.; Thompson, M. E.; Forrest, S. R. Nature 1998, 395, 151.

2. O'Brien, D. F.; Baldo, M. A.; Thompson, M. E.; Forrest, S. R. Appl. Phys. Lett. 1999, 74, 442.

3. Baldo, M. A.; Lamansky, S.; Burrows, P. E.; Thompson, M. E.; Forrest, S. R. Appl. Phys. Lett. 1999, 75, 4.

4. D’Andrade, B. W.; Forrest, S. R.; Chwang, A. B. Appl. Phys. Lett. 2003, 83, 3858.

5. Burrows, P. E.; Padmaperuma, A.; Sapochak, L. S.; Djurovich, P.; Thompson, M. E. Appl. Phys. Lett. 2006, 88, 183503.

6. Padmaperuma, A. B.; Sapochak, L. S.; Burrows, P. E. Chem. Mater. 2006, 18, 2389.

7. Vecchi, P. A.; Padmaperuma, A. B.; Qiao, H.; Sapochak, L. S.; Burrows, P. E. Inorg. Chem. 2006, 8, 4211.

8. Ha, M. Y.; Moon, D. G. Appl. Phys. Lett. 2008, 93, 043306.

9. Matsushima, T.; Adachi, C. Appl. Phys. Lett. 2006, 89, 253506.

10. Jeon, S. O.; Jeon, Y. M.; Kim, J. W.; Lee, C. W.; Gong, M. S. Org. Electron. 2008, 9, 522.

11. Kim, K. S.; Jeon, Y. M.; Kim, J. W.; Lee, C. W.; Gong, M. S. Org. Electron. 2008, 9, 797.

12. Jeon, Y. M.; Kim, J. W.; Lee, C. W.; Gong. M. S. Dyes Pigments 2009, 83, 66 .

13. Kim, K. S.; Jeon, Y. M.; Lee, H. S.; Kim, J. W.; Lee, C. W.; Jang, J. G.; Gong, M. S. Synth. Met. 2008, 158, 870.

14. Kim, J. H.; Jeon, Y. M.; Jang, J. G.; Ryu, S.; Chang, H. J.; Lee, C. W.; Kim, J. W.; Gong, M. S. Bull. Korean Chem. Soc. 2009, 30, 647.

15. Jeon, S. O.; Lee, H. S.; Jeon, Y. M.; Kim, J. W.; Lee, C. W.; Gong, M. S. Bull. Korean Chem. Soc. 2009, 30, 863.

16. Kim, K. S.; Jeon, Y. M.; Kim, J. W.; Lee, C. W.; Gong, M. S. Dyes Pigments 2009, 81, 174.

17. Jeon, S. O.; Jeon, Y. M.; Kim, J. W.; Lee, C. W.; Gong, M. S. Synth. Met. 2009, 159, 1147.

18. Jeon, S. O.; Yook, K. S.; Joo, C. W.; Son, H. S,; Jang, S. E.; Lee, J. Y. Org. Electron. 2009, 10, 998.

19. Padmaperuma, A. B.; Sapochak, L. S.; Burrows, P. E. Chem. Mater. 2006, 18, 2389.

20. Jeon, Y. M.; Lee, I. H.; Lee, H. S.; Gong, M. S. Dyes Pigments, in press.

21. Dunlap, D. H.; Parris, P. E.; Kenkre, V. M. Phys. Rev. Lett. 1996, $77,542$. 